\title{
POR UMA PSICOLOGIA SOCIAL ANTIRRACISTA: CONTRIBUIÇÕES DE FRANTZ FANON CONTRIBUTIONS OF FRANTZ FANON
}

\author{
Edelu Kawahala e Rodrigo Diaz de Vivar y Soler \\ Universidade Federal de Santa Catarina, Florianópolis, Brasil
}

\begin{abstract}
Atualmente no Brasil, principalmente por conta do surgimento de políticas públicas com o objetivo de diminuir as desigualdades raciais, as discussões sobre temas relacionados às questões raciais têm ganhado maior visibilidade. Em um país historicamente racista como o nosso, saberes que sustentam o mito da demo-

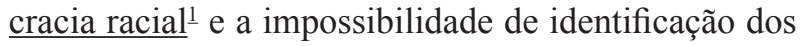
negros por conta da miscigenação seriam os principais argumentos usados para o impedimento da implantação de políticas como o programa de ações afirmativas tanto no ensino superior quanto no funcionalismo público, por exemplo. Por outro lado, surgem também importantes produções que irão intensificar estratégias de reparação das injustiças históricas cometidas até hoje. É diante desse cenário conflituoso que o livro Pele Negra, Máscaras Brancas é reeditado em língua portuguesa, chegando até nós como um instrumento de combate útil nos desdobramentos contemporâneos que a luta antiracista
\end{abstract} assume. Quer dizer, mais de que uma exposição teórica, o que Fanon no oferece é um mergulho na realidade das relações raciais do mundo contemporâneo. Seu texto quebra com todos os paradigmas de uma ciência positivista produzida não só no início do século XX, mas também nos dias de hoje. Embora, sua formação seja a psiquiatria, percebe-se ao longo do livro, um interessante diálogo com os estudos antropológicos e sociológicos. Não obstante, Fanon, procura falar também de um novo lugar epistemológico, na medida em que, propõe uma ruptura com esses saberes tradicionais concentrados no etnocentrismo em favor de uma nova possibilidade analítica que se dirige da periferia para o centro. Como se a voz a se insurgir nesse contexto discursivo estivesse localizada na realidade local para empreender uma crítica em torno da condição do negro na modernidade. Esse novo lugar epistemológico seria uma fala dos confins - para emprestarmos um conceito criado por Pelbart (2008) - inserida em um movimento provocativo de diagnóstico resumido no seguinte questionamento: o que é ser negro no mundo de hoje? Já no início da obra, o autor se posiciona como negro, e é a partir desse lugar que procura falar de todas as suas experiências existentes em uma sociedade racista, tal qual esta passagem descrita abaixo:
Os elementos que utilizei não me foram fornecidos pelos "resíduos de sensações e percepções de ordem, sobretudo táctil, espacial, cinestésica e visual", mas pelo outro, o branco, que os teceu para mim através de mil detalhes, anedotas, relatos. Eu acreditava estar construindo um eu fisiológico, equilibrando o espaço, localizando as sensações, e eis que exigiam de mim um suplemento. "Olhe um preto!" Era um stimulus externo, me futucando quando eu passava. Eu esboçava um sorriso. "Olhe um preto!" É verdade, eu me divertia. "Olhe um preto!” O círculo fechava-se pouco a pouco. Eu me divertia abertamente. "Mamãe, olhe o preto, estou com medo!" Medo! Medo! E começavam a me temer. Quis gargalhar até sufocar, mas isso tornou-se impossível. Eu não agüentava [sic] mais, já sabia que existiam lendas, histórias, a história e, sobretudo, a historicidade que Jaspers havia me ensinado. Então o esquema corporal, atacado em vários pontos, desmoronou, cedendo lugar a um esquema epidérmico racial. (Fanon, 2008, pp. 104-105)

Fanon deixa perceptível a influência de várias correntes teóricas importantes do período em que Pele Negra, Máscaras Brancas foi escrito. Pode-se perceber que ele foi influenciado pela psicanálise e também pelo marxismo; contudo, Fanon empreende uma crítica a esses dois saberes, afirmando que nenhuma dessas correntes epistemológicas pode dar conta da problemática das relações raciais, uma vez que reduzem a condição do negro ou a um complexo da sexualidade, como no caso da psicanálise, ou então a meras manifestações dos modos de produção do regime capitalista, como no caso do marxismo. Fanon irá falar que a condição do sujeito negro é singular, porque ele está tanto cultural quanto historicamente em uma posição de inferioridade e sujeição ao colonizador branco.

Para o autor, a colonização e o racismo alteram profundamente a subjetividade do negro. Apesar desse recorte psicológico, não há reducionismo; a perspectiva analítica empreendida por Fanon é psicossocial, uma vez que compreende o sujeito como produto de uma realidade econômica e social. Afirma Fanon então que a luta dos negros só irá efetivar-se nos planos objetivos e subjetivos no intenso e arenoso campo das relações e das práticas sociais existentes a partir da historicidade dos indivíduos e de seus respectivos modos de produção subjetiva. 
Fanon divide seu livro em oito capítulos, nos quais aprofunda diversos temas até hoje pertinentes como sexualidade, relações afetivas interétnicas e relações de poder interraciais. Ele inicia sua exposição falando da importância da linguagem na constituição dos sujeitos negros colonizados. Segundo Fanon, a mesma linguagem que os produz equivocadamente precisa ser rechaçada para que o negro liberte-se de uma negritude tipicamente representativa e estereotipada. Ou seja, falar a língua, agir e experienciar a cultura negra significa abrir mão e recusar uma ideologia produzida pelos brancos. Nesse sentido, Fanon se mostra atual, afinal, ainda hoje, apesar de pensadores como Rita Segato, Stuart Hall e Boaventura Souza Santos apontarem a urgência de novas epistemologias relacionadas com realidades sociais e locais, a produção de saber e mesmo as agendas temáticas das instituições de pesquisa, com raras exceções, passam longe de temas como as relações raciais.

Fruto de uma hierarquia cultural sustentada na supremacia branca, a cultura negra continua, quando abordada, representada de forma folclorizada e preconceituosa, inclusive por cientistas, que iniciam as suas pesquisas a partir de preconceitos estabelecidos e olhares etnocêntricos. Assim, as políticas públicas que possibilitam a formação desses "estranhos", até então objetos de pesquisa, em pesquisadores, deverão permitir a construção de um conhecimento sobre a cultura negra enquanto tema recorrente nos centros de pesquisa, para que novas epistemologias possam ser concebidas.

Nos dois capítulos seguintes, "A Mulher de Cor e o Branco" e "O Homem de Cor e a Branca", Fanon aborda os aspectos subjetivos e políticos das relações interétnicas. Apontando para um ideal de embranquecimento como a mola propulsora desse desejo, que não é metafísico, mas construído nas relações sociais e políticas, ele entende que o racismo desencadeia no negro o desejo de embranquecer através de seus descendentes. Sendo assim, as mulheres negras irão buscar relacionarse com homens brancos para que seus filhos sejam mais claros. Da mesma forma, o homem negro vê na mulher branca o seu passaporte para o mundo civilizado. Para tanto, esse se torna um objeto novamente submetido à selvageria e ao primitivismo. Mais de que desejo e afetividade, o encontro com o homem ou a mulher branca será, antes de qualquer coisa, uma fuga da miséria e da exclusão. Isso é uma ilusão, aponta Fanon, pois tanto o negro quanto o branco, ao se relacionarem a partir desta hierarquia de raças, não poderão vivenciar um relacionamento efetivo verdadeiro, e o fantasma do racismo irá sempre interpor-se a eles.

Ao longo do livro, Fanon argumenta sobre a importância dos acontecimentos sociais na constituição dos sujeitos. Embora negros e brancos implicados nas relações raciais não sejam meros fantoches dessa condição, seja por sucumbirem ou rebelarem-se contra ela, não será possível passar impune por esse processo histórico e social. Nesse sentido, no melhor estilo de que "a nossa responsabilidade é muito maior do que poderíamos supor, pois ela engaja a humanidade inteira" (Sartre, 1987, p. 07), Fanon nos convida a agir pelos caminhos da liberdade e da solidariedade. Fanon (2008) fala que não há como o negro escapar da negritude, pois ela estará sempre lá na sua pele como um signo de um renegado. Sendo assim, ao negro resta só um caminho, que é o da ação, e uma vez comprometido com a luta antirracista, essa luta se propaga, atingindo novos contornos e contaminando novos sujeitos, pois, segundo ele, é preciso ser solidário a todos. Para Fanon, não há racismos, mas somente um, e que, portanto, na luta contra todas as opressões, se devam unir grupos minoritários como judeus, árabes, ou ciganos, por exemplo.

Nesse sentido, Fanon faz uma crítica a Mannoni, quando esse afirma que o racismo seria um fenômeno de subalternos, e não da elite francesa. Para o autor, não é possível que somente uma parcela da população seja racista sem que essa elite não legitime determinadas práticas. O que Mannoni faz não é diferente do que vemos hoje na contemporaneidade; nega-se o racismo para que ele seja invisibilizado e, assim, permaneça ativo, embora camuflado e recoberto por uma economia de poder praticamente imperceptível, mas que é muito eficaz. Hoje, um dos principais argumentos daqueles que se posicionam contra as políticas de ações afirmativas é que o Brasil não é um país racista e, portanto, todas as políticas de discriminação positiva só irão racializar uma nação na qual convivem harmoniosamente todas as culturas e povos. Esses intelectuais conservadores afirmam que o problema da exclusão social dos negros se deve a uma questão de classe, e não de raça.

No que diz respeito a esta polêmica questão de classe e raça, Fanon fará uma severa crítica a Sartre, quando esse afirma ser a luta antirracista como um "tempo fraco" de uma progressão dialética. Fanon, embora possua em sua formação uma importante influência marxista, compreende a negritude como um fim. Para ele, então, é preciso ir mais fundo, é preciso um respeito verdadeiro à cultura e à pele do negro, ao modo de pensar do negro, é preciso que o negro seja livre, que não seja mais um intelectual negro, um artista negro; o adjetivo negro precisa desaparecer, e isso só acontecerá se o negro e sua negritude forem vivenciados por todos.

Fanon fala da diferença e da importância do respeito e do reconhecimento enquanto categorias de um mundo mais justo, no sentido equitativo da palavra. De certa forma, ele antecipa Boaventura Souza Santos em sua famosa frase: "as pessoas têm direito a ser iguais sempre que a diferença as tornar inferiores, contudo têm também direito a ser diferentes sempre 
que a igualdade colocar em risco as suas identidades" (Santos, 1997, p. 10). Com isso, Fanon aponta para a necessidade de novas práticas que possam compreender e intervir nas demandas da população negra. Evidentemente, não se trata de criar uma ciência específica para os negros, mas de incluí-los como "diferença." Para exemplificar, o autor faz um escrutínio sobre a Psicanálise, e conclui que ela não se aplica à população negra, já que o modo de relação familiar e o drama burguês do complexo de Édipo, bases dessa teoria, não se efetivam no contexto da cultura negra e, como consequência, a psicanálise consegue no máximo uma patologização dessa população.

Por fim, Fanon reivindica a liberdade enquanto uma possibilidade concreta ao afirmar que:

$\mathrm{Eu}$, homem de cor quero apenas uma coisa: Que jamais o instrumento domine o homem. Que cesse para sempre a dominação do homem pelo homem. Isto é, de mim por outro que me seja permitido descobrir e querer o homem onde quer que ele se encontre. (Fanon, 2008, p. 265)

Dessa forma, a obra de Fanon é essencial para a compreensão psicossocial das relações raciais, sobretudo no Brasil de hoje, quando o Estado assume oficialmente o histórico racista e quando políticas de reparação social passam a ser alvo de severas críticas. Mais do que nunca, é necessário que pensemos a problemática do racismo a partir das suas mais diversas consequências.

\section{Nota}

1 De acordo com Célia da Silva (2002), esse mito mascara a realidade por meio de um processo ideológico que preconiza a igualdade de direitos e oportunidades tanto para brancos quanto para negros e mestiços. O mito da democracia racial seria então uma ferramenta que impede uma problematização dos fatores de exclusão e de repressão presentes nas relações raciais, acentuando o caráter paternalista das relações de classe e de raça.

\section{Referências}

Silva, A. C. (2002). Ideologia do embranquecimento. In I. Costa Lima \& J. Romão (Orgs.), As idéias racistas, os negros e a educação (Série Pensamento Negro em Educação, Vol. 1, pp. 13-22). Florianópolis: Atilènde Editora.

Fanon, F. (2008). Pele negra, máscaras brancas. Salvador: EDUFBA.

Pelbart, P. P. (2009). Fala dos confins: o lugar da literatura na obra de Foucault. Revista Cult, ano 12, 134, 51-53.

Santos, B. S. (1997). Toward a multicultural conception of human rights. Zeitschrift für Rechtssoziologie, 01(18), 1-14.

Sartre, J. P. (1987). O existencialismo é um humanismo. In J. A. M. Pessanha (Org.), Sartre (pp. 33-107, Coleção Os Pensadores, fascículo 57). São Paulo: Nova Cultural.

Recebido em: 18/08/ 2008

Revisão em: 06/09/2009

Aceite final em: 28/03/2010

Edelu Kawahala é Mestre em Psicologia pela UFSC e atualmente é aluna especial do Doutorado em Psicologia pela UFSC. Consultora para projetos de Pedagogia Multirracial na Organização Não Governamental Núcleo de Estudos Negros de Florianópolis/SC. Endereço: Rua Vereador Mário Coelho Pires, no 221. B1. A, apto. 1302. São José/SC, Brasil. CEP: 88101-280. Email: edelukaw@hotmail.com

Rodrigo Diaz de Vivar y Soler é Bacharel em Psicologia pela UNESC e atualmente é aluno do Mestrado em Psicologia pela UFSC. Email: diazsoler@gmail.com

\section{Como citar:}

Kawahala, E. \& Vivar y Soler, R. D. (2010). Por uma psicologia social antirracista: contribuições de Frantz Fanon. Psicologia \& Sociedade, 22(2), 408-410. 